\title{
O TEATRO INSOLITO DE QORPO SANTO
}

\author{
Moacyr Flores
}

Há um silêncio pesado sobre as obras de Qorpo Santo (1829-1883), rompido apenas de vez em quando com uma crítica mordaz, uma crônica jocosa, pois seus contemporâneos consideravam-no um excêntrico.

Graças a Dario Bitencourt, possuidor de 2 volumes da Enciclopédia, e a Olyntho Sanmartin, dono de um volume, foi possível ao professor Guilhermino César fixar e comentar com propriedade os textos das comédias de Qorpo Santo. Posteriormente, sócios do CIPEL encontraram mais 3 volumes no castelo de Pedras Altas, possibilitando a segunda edição mais ampla.

Flávio de Aguiar escreveu "Os Homens Precários", analisando as obras de Qorpo Santo como um teatro marginal em sua época, um teatro que é um grito contra a injustiça.

Em nenhum momento Qorpo Santo teve a intenção de elaborar um teatro de contracultura ou de protesto contra o sistema. Suas comédias insólitas transmitem de maneira incoerente, em linguagem coloquial, os desejos de recuperar seus bens materiais em mãos de um procurador; seu desamparo ao ser abandonado pela família; seu desespero porque serve de mofa por suas esquisitices; suas contradições entre uma moral puritana e seus desejos carnais incontroláveis.

De acordo com a Enciclopédia, José Joaquim de Campos Leão, depois Qorpo Santo, nasceu às 11 horas do dia 19 de abril de 1829, em Triunfo. Quando ficou órfão de pai, trabalhou no comércio de Porto Alegre, a partir de 1840. Depois, em 1851, 
desempenhou a tarefa de professor em Santo Antônio da PatruIha, onde participou de uma Loja Maçônica.

Destacou-se como professor em Alegrete, onde chegou a ser eleito vereador em 1860. Casou em 1856 com D.' Inácia Maria, que também exerceu o magistério. Qorpo Santo criou uma nova grafia, que serviu de chacota para seus adversários: substituiu o $\mathrm{PH}$ pelo $\mathrm{F}$, que tinha o mesmo som, a letra $\mathrm{C}$ para $\mathrm{Q}$, tirou fora as letras dobradas e o $\mathrm{H}$ mudo no início de palavras. $\mathrm{O}$ som forte de C, passou para S e o som brando de S, para Z. Assim escreveu parte de sua Enciclopédia.

Suas poesias são irreverentes, consideradas como exóticas e paradoxais por seus contemporâneos, que versejavam lacrimosas e amorosas composições, no melhor estilo do romantismo tardio.

Na poesia seguinte, nota-se a irreverência e a agressividade do poeta:

\section{A UMA BARONESA}

Filha és de Visconde;

Eu - de professor pobre:

Sinto não ser nobre,

- de raça ou sangue...

Pra que não mangue

Alguém - comigo,

Trago um umbigo,

Bem retovado,

De couro rapado!

De ponta aguda,

Que põe muda

Qualquer mulher

Que mete a colher...

Não sei a onde!

Assim, Baronesa

Se não sou nobreza

$\mathrm{Na}$ alma a tenho;

$E$ não convenho

- Que se me maltrate;

Ou que se me mate! 
Enquanto os poetas românticos passeavam pelos campos, suspirando por ninfas, sentindo nas faces os zéfiros campesinos, Qorpo Santo apresenta um passeio diferente:

\section{PASSEIO}

Fui ao Campo ver tatus;

Achei - Tambicus.

Fui ao mato ver bujias;

Achei - enguias.

Fui à fábrica ver bijus;

Achei - bagadus.

Também busquei - pitangas;

Achei - mangas;

Doutras - procurei tudo;

Achei - veludo!

Cansado fiquei;

À cama voltei:

A cama deitar,

Fui repousar!

Em sua poesia Visita à Igreja, Qorpo Santo abençoa as pessoas, pois andava com mania de santidades.

\section{VISITA A IGREJA}

Fui hoje à missa,

Por ser sábado;

E de preguiça,

Comi cágado!

Não de preguiça

Mas de avareza

- Comi Teresa;

- Comi lingüiça!

Assim, ao sábado,

Mais não irei;

Nem comerei, $\mathrm{O}$ duro cágado! 
Mas, se eu for, Inda outra vez, - Melhor rez -

Terá meu favor!

Várias pessoas

- Lá encontrei;

A todas botei

A minha benção!

Algumas meninas

De cores mui finas, De livros - rezavam

A Deus oravam!

Poucas velhas, Bem enfeitadas, Eram tornadas, - Mel de abelhas!

$$
\begin{aligned}
& \text { Homens - poucos; } \\
& \text { Meninos - alguns ... } \\
& \text { O que de loucos, } \\
& \text { Ali - estariam! }
\end{aligned}
$$

Augusto Porto Alegre, em suas crônicas, lembrou que Qorpo Santo era possuidor de gênio afável e caridoso, por motivos desconhecidos, tornou-se depois um contemplativo, apresentando uma personalidade original, pondo à mostra o desequilíbrio mental que o notabilizou.

Esta reviravolta ocorreu em 1862, quando foi licenciado do cargo de professor da província. Dois anos depois, um exame médico considerava-o apto a retornar ao magistério. Mas o tormento de José Joaquim continuou porque o juiz Antônio Correia de Oliveira deu prosseguimento ao processo, até que em 1868 a família levou-o ao Rio de Janeiro, internando-o no Hospício D. Pedro II e na casa de saúde do Dr. Eiras. Depois de acurados exames, os médicos concluiram que era melhor mantê-lo fora de reclusão. Retornou a Porto Alegre, mas foi intimado por novo processo e 
declarado interdito, ou seja, inapto a gerir os bens e a família, que ficaram sob a tutela do juiz. Qorpo Santo acusou a esposa e o juiz Antônio Correia de Oliveira de adultério, denunciando que o processo era apenas um plano maquiavélico para afastá-lo da família e de suas propriedades.

Durante este período, escreveu suas peças teatrais que podem ser consideradas como as primeiras no mundo a se caracterizarem pelo absurdo de suas cenas e personagens.

Infelizmente, Qorpo Santo escreveu-as em Porto Alegre, capital da Província de São Pedro do Rio Grande do Sul. Se as tivesse elaborado em Paris ou Londres, seria considerado o criador do teatro do absurdo. Comparado com os autores de sua épo$\mathrm{ca}$, que usavam uma linguagem retórica e cheia de adjetivos. Qorpo Santo é o único que pode ser representado na atualidade, porque suas comédias tratam da angústia gerada pela injustiça e pela perseguição. Seu teatro é autobiográfico, revelando seu sofrimento, sua solidão e a incompreensão de seus semelhantes.

A comédia "As Relações Naturais" tem como tema o drama de um chefe de família que descobre que sua casa foi transformada em um bordel, que sua esposa é amante do criado e que suas filhas recebem estranhos em casa. No primeiro ato, o chefe de família, que também escreve peças de teatro, busca uma compensação com outras mulheres, enquanto a esposa vai com as filhas à novena. Pouco a pouco surge a angústia do marido traído, até que, cinicamente, o criado auxilia as mulheres a enforcarem o patrão. As moças ameaçam enforcar a toda a autoridade que tentar estorvá-las.

Na comédia está o drama de Qorpo Santo: o adultério de sua esposa com o juiz e o abandono de seus filhos.

Em "Mateus e Mateusa", comédia em um ato, Qorpo Santo trata da solidão a dois, a velhice de esposos que deveria ser de amparo e de amor, transforma-se numa luta diária, da qual as filhas sabem tirar proveito, bajulando o velho pai. O velho Mateus tem uma fala que caracteriza a temática:

"Coitado, pobre de quem é velho! As mulheres fogem e as filhas desaparecem." 
Quando a mulher quer abandoná-lo, Mateus argumenta que são casados pelas leis tanto civis como canônicas, e que ela tem obrigação de aturá-lo. A mulher responde que ninguém mais respeita o Código Criminal e que os Doutores nele cospem e escarram todos os dias, como se fosse uma nojenta escarradeira. $O$ veIho Mateus junta o livro de Leis e diz que suas folhas serão úteis cada dia em que suas tripas revelarem a necessidade de ir à latrina. Como a mulher não dá importância à lei escrita. Mateus faz valer a lei da cacetada, dá paulada e dá bengalada.

Qorpo Santo criticou assim a sociedade de seu tempo, afirmando que a falta de emprego das leis traria fatalmente a destruição em vez da edificação e o regresso, em vez do progresso.

Novamente, Qorpo Santo autobiografou-se na comédia "Hoje sou um e amanhã outro", quando o ministro Eleutério comenta com o rei Dourado sobre espiritismo e reencarnação. Ele, o ministro, já fora um poderoso em outra vida, enquanto o rei, na outra encarnação, fora um simples vassalo e criado. O ministro continua sua arenga fornecendo mais dados sobre um homem predestinado que vivem Porto Alegre, que a todos honra, ilustra e moraliza. O rei pergunta:

"- Mas quais os seus princípios, ou os de sua vida?

-É Filho de um professor de primeiras letras; seguiu por algum tempo o comércio; estudou depois e seguiu por alguns anos a profissão de seu pai, roubado-lhe pela morte, quando contava apenas de 9 a 10 anos de idade. Durante o tempo do seu magistério, empregou-se sempre no estudo da História Universal, da Geografia, da Filosofia, da Retórica - e de todas as outras ciências e artes que o podia ilustrar. Estudou também um pouco de Francês e do Inglês; não tendo podido estudar também Latim, conquanto a isso desse começo, por causa de uma enfermidade que em seus princípios 0 assaltou. Lia constantemente as melhores produções dos Poetas mais célebres de 
todos os tempos; dos Oradores mais profundos; dos Filósofos mais sábios e Retóricos mais briIhantes ou distintos pela escolha de suas belezas; de suas figuras oratórias! Foi esta a sua vida até a idade de trinta anos."

Continuando, o ministro explica que este homem abandonou o magistério e começou a produzir de todos os modos, e profetizar. Este homem extraordinário viveu por espaço de um ano em um retiro, onde produziu numerosos trabalhos sobre todas as ciências, compondo uma obra de 400 páginas que denominou E... O ministro gagueja e não consegue se lembrar do nome da obra, mas recorda-se das iniciais do fabuloso profeta: Q... S...!

Em seus delírios esquizofrênicos, Qorpo Santo considerou-se o coração do mundo, a cabeça do universo, um desses raros talentos que só se admiram de século em século.

Desce o pano no fim do 30 ato, depois que o rei e a rainha declamam:

"- Sempre a Lei, a Razão e a Justiça triunfam da perfídia, da traição e da maldade."

A melhor obra teatral de Qorpo Santo é "Eu sou vida; eu não sou morte", onde, no primeiro ato, Linda e Lindo iniciam uma declaração de amor nos moldes do romantismo, tão do agrado da época, para depois descambarem para um diálogo absurdo, prenhe de alusões ao sexo e com palavras de duplo sentido. Este diálogo violento, desenvolvido em linhagem coloquial, feria a pudicícia da sociedade local. Entra em cena um rapaz que quer matar Lindo, os dois lutam até que uma nuvem vindo do céu, com trovöes e relâmpagos, assusta os dois contendores, que se ajoeIham enquanto gritam:

\section{"-Punição divina."}

O segundo ato começa com mútuas acusações entre Lindo e Linda, até que entra novamente o rapaz ameaçando o amante. Pelo rápido diálogo, despido de retórica e de adjetivos, fica-se sa- 
bendo que Lindo seduziu Linda e abandonou-a. O rapaz visitante casou com ela, adotando inclusive a menina que nasceu, como se fosse sua filha. $\mathrm{O}$ sedutor apareceu mais tarde e Linda abandonou o esposo, fugindo com seu antigo amante. $\mathrm{O}$ marido procura reaver sua esposa e mata o rival.

Nesta peça, Qorpo Santo coloca todo o drama de sua vida: abandonado por sua esposa D. Inácia Maria, que, junto com o juiz Antônio Correia de Oliveira, moveu-lhe o processo que interditou sua pessoa e seus bens. A peça termina com a fala do marido de Linda, que é um grito de desespero de Qorpo Santo:

"-... Eis como Deus ajuda a quem trabalha! Depois de milhares de trabalhos, incômodos, perdas e perigos! Depois de centenas de furtos; roubos e as mais negras atrocidades! Depois de uma infinidade de insultos; penas; crueldades; o que não pude vencer, ou fazer triunfar com a pena, razões, discursos, acabo de fazê-lo com a espada!"

Não podendo eliminar fisicamente o juiz que lhe tirou os bens e a família, Qorpo Santo matou-o teatralmente.

O dramaturgo satiriza a burocracia do Império, na comédia intitulada "Um credor da Fazenda Nacional", em que ele próprio é o credor que tenta cobrar o que Ihe deve o governo pelo aluguel de uma casa. No primeiro ato, mostra como um major do exército consegue receber 0 aluguel com facilidade, enquanto que ele retorna diversas vezes à repartição, onde não sabem informar sobre o andamento de seu processo. No final, só há uma solução: tocar fogo na repartição pública.

A peça "Um assovio" apresenta uma empregada perseguida pelo sogro do amo, antigo criado. A pobre mulher não tem tempo para nada, porque é mandada e chamada por todos a qualquer momento. Por não ter executado as tarefas ordenadas pelo patrão, ela não pode sair da sala, impedida por ele e mais um amigo. Ela, sabendo que os dois e mais o sogro são poltrões, puxa de um punhal e avança para eles, que caem no chão. A criada, com a arma na mão, declama: 
"- Quando a força da razão, do direito e da justiça, empregada por atos e por palavras não for bastante para triunfar, lançai mão do punhal... e lançai por terra os vossos indignos inimigos, como fiz e vedes a estes trêz algozes."

A correção das injustiças sociais é uma constante nas obras de Qorpo Santo, refletindo sua angústia oriunda dos processos indignos de que foi vítima.

"Certa entidade em busca de outra" apresenta uma família desfeita, em que Brás, todos os dias, carrega uma nova mulher para dentro de casa. No primeiro ato, este homem se associa com o Diabo para destruir os maus. O Diabo traz as armas do Poder e da Vingança, enquanto Brás empunha a espada da Justiça, o revólver do Direito e o punhal da Razão. Os dois armam planos de vingança contra os traidores, bárbaros e assassinos que tudo roubam de Brás, tudo comendo, enquanto ele trabalha para sustentá-los. Mas entra Micaela e o personagem Brás se esquece de suas vinganças, levando-a para o quarto. Satanás, chocado com a imoralidade e a audácia do casal, tranca-os no quarto, carregando a chave. Os dois arrombam a porta para saírem, encontrando o fiIho de Brás, que não quer pedir a bênção a Micaela, apresentada como se fosse sua mãe. O filho agride a mulher a bengaladas, terminando assim a comédia.

"Lanterna de fogo" é a comédia em 3 atos e 2 quadros, na qual Qorpo Santo narra as caóticas desventuras de Robespier em busca de uma lanterna, deixada em testamento por seu pai, ora há 15 dias, ora há dez anos. Os diálogos se entrecruzam criativamente numa atmosfera sombria de não-senso, com frases rimadas, palavras que surgem por analogias metafóricas.

Robespier profere longos discursos incoerentes sobre Deus e as ações boas e más dos seres humanos, relatando a história de um homem assaz notável por sua ilustração, erudição, virtude, saber e prudência, que sofreu ataque à sua pessoa e bens; queixouse ao chefe de polícia, que não Ihe deu importância. O monarca, sabendo da injustiça, ordenou o recolhimento do chefe de polícia ao hospício, porque só quem não estivesse em seu perfeito juízo deixaria de atender às súplicas de um mártir. Neste pequeno en- 
trecho, o pobre mártir é o próprio Qorpo Santo. O personagem profético, Robespier, transfigura-se em velho, entrando com seu linguajar insano e colocano-se no papel de autor da peça, fazendo assim o teatro do próprio teatro:

"... Vamos entretanto continuar a de escritor, até acabar este quadro ou esquadro da minha célebre comédia. (Pega na pena e abre um livro.) Ui! que diabo tem a barriga? Será figa ou ferida? Sinto-a toda a mexer e dentro a se revolver... Que diabo! Estou assustado! Querem ver que é filho! Mas eu não comi milho! Apenas provei feijão! Como diabo! Ai! só se foi do leitão! (Largando a pena, depois de ter escrito algumas linhas e gritando e correndo pela sala toda:) Estou pobre! Estou pobre! Quem me cobre? Quem me acode! Aqui do Rei! Já não sou Rei! Ai! Ai! Ai! Estou doente; sou padecente. (Cai como desmaiado e ronca.)"

Os demais personagens acham que o velho morreu de tanto escrever comédia, romances e tragédias. Uma mulher acode o veIho, que se transforma em visconde ao entrar seu filho perdido. Robespier descobre que a lanterna, deixada em testamento por seu pai, são os olhos da mulher.

"Um parto", comédia em 3 atos, inicia com o personagem Cário dizendo que "o sábio beija, o néscio arqueja, porque aquele viveu em Deus e este com o diabo". Cário come biscoitos e pães em forma de estrela, turíbulo, naveta, barretina e coração, que servem de analogias a reflexões sobre religião, veneno e suicídio. Cário sai de cena e entra Florberta com longo discurso incoerente, reclamando que foi grosseiramente recebida pelo dono de uma casa. Entra Cário falando que o querem manter amigado, sem que isso possa ser. Retira-se dando piruetas, para retornar dizendo:

"Como se transtornam as cousas deste mundo! Quando pensaria eu que indo à casa de um médico fazer uma ligeira visita, havia de transtornar uma comédia? Quando é preciso ao homem, que 
se dedica a composições intelectuais, ter regime certo ou invariável! Uma visita transtornou uma comédia; qualquer ação obsta à conclusão do mais importante trabalho. Quão bem foi começada esta comédia, e quão mal acabada vai! Já nem posso chamar a isto mais comédia... Enfim, vereis se posso consertar minhas idéias e prosseguir então. (Sai.)"

Qorpo Santo não conseguiu consertar suas idéias nos dois atos seguintes. $O$ segundo ato se desenrola no quarto de 4 estudantes que discutem com disparates. No terceiro ato, o estudante mais velho dá conselhos, ensina, se faz de santo, de filósofo, até que corre com os companheiros do quarto, porque são horas de ir para a escola, terminando assim a caótica comédia, que possivelmente começou enfocando um acontecimento entre Qorpo Santo e sua esposa.

Na peça "A separação de dois esposos", o marido Esculápio briga por qualquer motivo com sua esposa Farmácia. A mulher é difícil de ser contentada até pelas 3 filhas. Quando está sozinha, espera anciosa a vinda do amigo Fidélis, que traz uma carta falsa para Esculápio. Quando ele entra e recebe a carta em branco, tendo uma coroa como timbre, considera-se nomeado presidente da província. Ele ri, salta, pula de alegria. A mulher se irrita, os dois brigam e o marido sai armado de punhal para pegar uma mulher à força. No segundo ato, Esculápio retorna ensangüentado, roupa rasgada e dizendo que cometeu um crime, concluindo depois de longo discurso:

\footnotetext{
"... Mas quem pode viver sem regras ou sem preceitos que regulem seus direitos; seus deveres; seus poderes? Seriam as sociedades um caos. Anarquizar-se-iam e logo depois - destruir-se-iam."
}

A mulher, cansada de tanto sofrimento, convida-o para morrerem juntos, procurando a felicidade no céu.

No terceiro ato, os criados Tatu e Tamanduá esclarecem que certos esbirros de polícia queriam separar os dois esposos, levan- 
do o marido a sofrer muito e a mulher de professora pública a ficar uma simples cozinheira e lavadeira. Não podemos nos esquecer que a esposa de Qorpo Santo foi professora.

\section{"Tatu - ... Sirva este fato de lição e que aprovei- te a quantos pretenderem, ou tentarem - divorciar esposos."}

Logo após, o criado Tamanduá declara sua paixão por Tatu, que o repele:

\section{"Tatu - O diabo! Tu estás variando! Quanto ao espírito, nem todos os demônios que habitam por todas as regiões são capazes de nos divorciar e quanto ao parir... mais devagar; eu sou homem; (pondo-lhe a mão no ombro) não sou mulher! $E$ tu hás de saber que é o vício mais danoso que o homem pode praticar!"}

Os dois brigam e termina a comédia, que retrata o drama íntimo de Qorpo Santo e coloca pela primeira vez no teatro brasileiro o homossexualismo.

Em 1877, Qorpo Santo publicou em sua Enciclopédia a mais absurda de suas comédias: "O marido extremoso"; ou o "Pai cuidadoso", com grande número de personagens. No primeiro ato, Régulo e Remo combinam de roubar a todos, depois realizam experiências de se baterem com pau e cadeira. Sancho entra na pacandaria e termina sendo roubado pelos dois. $\mathrm{O}$ segundo ato acontece num baile, com mulheres mostrando as pernas quando dançam. Há várias expressões regionalistas ditas pelos dançantes. Os pares se retiram para os quartos, enquanto que os músicos se queixam que os outros se divertem e eles tocam. As escravas encarregadas da limpeza reclamam da sujeira e tudo abandonam. O terceiro ato é numa sala de esgrima, onde alguns estudantes se exercitam com florete, espada e lança até que entra o mestre e todos baixam as armas. A ação do quarto ato desenrola-se numa casa de sapataria e alfaiataria, em que os mestres e apren- 
dizes, cansados das grosserias, agressões e roubos dos fregueses, fazem um pacto de matarem os fregueses à entrada, a fim de roubarem-nos, não precisando mais trabalhar como sapateiros ou alfaiates. No quinto ato, Pedro está preso injustamente por falsas calúnias. $O$ presidente considera o chefe de polícia culpado porque acobertou as injustiças. O presidente, antes de sair para ver os fogos, conclui a comédia dizendo:

"- Quanto é doce o ser Pai de Família e com ela viver harmoniosamente - só pode conhecer quem como eu neste momento se enche de prazer e de júbilo."

Esta, peça isolada das demais, pode parecer totalmente incoerente, pois seus atos isolados não estão ligados por trama ou ação, mas comparando-a com as outras, veremos que ela reproduz, em pequenos lampejos, as angústias de Qorpo Santo. O primeiro ato é o roubo da propriedade; o segundo é o erotismo e a licenciosidade, o terceiro corresponde à violência, o quarto representa o protesto das vítimas que sofrem injustiças e resolvem adotar a pena de Talião, e, finalmente, o quinto ato apresenta a figura da autoridade maior, esperança de todos os oprimidos e sofredores, que faz e impõe a justiça. Estes atos exploram as temáticas constantes nas peças do dramaturgo do absurdo.

Qorpo Santo deixou incompleta a comédia "Uma pitada de rapé", que começa com a filha bajulando o velho pai, doido por rapé, porque quer lhe apresentar o namorado.

"O hóspede atrevido" ou o "Brilhante escondido" inicia com divagações filosófico-religiosas do personagem Ernesto, que parece ser o dono da casa, onde pessoas entram para vê-la; também entram e saem diversas pessoas, entre elas o poeta Jorge, casado com Eulália, o hóspede Alberto, bêbado e sem dinheiro, o o criado Leon e um amigo da família, chamado Paulo. Alberto pede dinheiro a Paulo, dando-Ihe como penhor um brilhante. Eulália, que saiu com Jorge, retorna amorosamente com Ernesto. O hóspede Alberto briga com o criado Leon, por causa da roupa mal escovada, chegando a esbofetear o serviçal. Paulo briga com $\mathrm{o}$ agressor que pede o brilhante, recebendo uma negativa. Paulo e 
Leon, armados de revólver e pau, atacam o hóspede que grita por socorro. Entram os soldados, querendo levar todos presos para explicações na polícia. Paulo tenta comprá-los com dinheiro. 0 criado acusa Alberto:

\section{"Leon - E a mim quis me fazer de mulher."}

Os soldados arrastam os quatro para o quartel da polícia. 0 próprio Qorpo Santo admite que esta comédia é apenas um borrão que deve passar pelas correções necessárias, pois foi escrita das 23 horas do dia 30 até às 3 horas da madrugada de 31 de janeiro de 1866

O que pretende Qorpo Santo com esta comédia? Eulália é casada com Jorge, mas faz uma cena inteira de amor com Ernesto. A briga pelo brilhante empenhado não tem ligações com as açoes de Ernesto, Jorge e Eulália. Possivelmente, Qorpo Santo pretende mostrar que em um lar, onde há adultério, pode acontecer todas as iniqüidades, sem que o dono da casa tome conhecimento.

A comédia "A impossibilidade da santificação" ou a "Santificação transformada" é precedida por uma explicação confusa de Qorpo Santo, em que está patente seu desequilíbrio mental. $\mathrm{O}$ autor escreve um esboço da comédia, narrando os infortúnios de um homem, com 27 anos, que casou com uma moça de 22, filha de certa viúva. Os dois dedicaram-se ao magistério e quando morreu a mãe da moça, eles deixaram de ensinar e passaram a brigar entre si, como se fossem grandes inimigos, porque o marido estava divino e a mulher não passava de uma humana. Os esposos se separaram, levando a mulher os filhos. Ele se retirou da vida mundana, passando a estudar o direito pátrio e as Sagradas Escrituras, produzindo admiravelmente sobre diferentes assuntos. Este homem, apesar de culto, inteligente e rico, começou a passar necessidades, maltratado por uma escrava que recebera proposta de liberdade.

Qorpo Santo revela, nesta explicação inicial, uma autobiografia ideal, exteriorizando suas confusões mentais diante dos acontecimentos, em que se envolvia no seu dia-a-dia. 
Augusto Porto Alegre revelou, em suas crônicas, que, em .1873, Qorpo Santo resolveu se dedicar ao comércio e publicou nos jornais o seguinte anúncio:

“De 15 do p. f. mês de fevereiro, em diante, estabeleço como já anunciei o negócio de líquidos, secos e molhados. Fazendo-o sem capital pecuniário, e com o fim de fundar uma Igreja a São José de Leão - em uma das mais altas e próximas montanhas à esta cidade..."

Não existe no hagiológio cristão nenhum São José de Leão, de onde se conclui que este novo santo é o próprio JOSÉ Joaquim de Campos LEÃO, lutando para que sua santificação seja reconhecida, além de seu espaço irreal.

No primeiro ato, o personagem QS deve uma conta e se nega a assinar um documento da dívida. No segundo ato, surge o amo do caixeiro ameaçando de citar QS na justiça; este expulsa os dois comerciantes, dizendo que eles ofereceram as roupas para que fossem pagas mais tarde. A filha Malévola chama a atenção de QS e é excomungada pelo pai. Ficando sozinho, ouve vozes de mulheres em outro cômodo da casa; elas estão roubando o que Ihe pertence. $O$ terceiro ato parece ser uma reunião na casa de QS com personagens que tentam mulheres com presentes (seriam as filhas de Qorpo Santo?) ou fazem reflexões estapafúrdias sobre moral, leis, civismo e religião. Duas velhas se queixam dos homens que só querem meninas. No final, o personagem Ridinguínio recebe uma carta de uma mulher e exclama, voltando-se para o público:

"- Não há dúvida, comecei por Comédia e acabo por Romance! Representar-se-á portanto em todo o mundo habitado, pela primeira vez uma mesma peça teatral tríplice chamada - Comédia, Romance e Reflexão! (Bate nas palmas até cair o pano.)"

Os contemporâneos de Qorpo Santo não quiseram representar esta novíssima peça teatral, que é o testemunho da desorientação mental do autor. 
$\mathrm{Na}$ comédia em dois atos longos, com muitos personagens, intitulada "O marinheiro escritor", o dramaturgo reuniu fragmentos de sua vida, tais como brigas com escravos, mulheres sendo cortejadas por outros homens, funcionários públicos que negam direitos dos peticionários e desconhecem o próprio trabalho. A peça termina com o personagem de nome Leão chicoteando o juiz, meirinho e escrivão:

\section{"Leão - Eis o prêmio que tarde ou cedo esperar sempre devem os criminosos...'}

Assim Qorpo Santo (Leão) se vinga teatralmente da Justiça que the tomou seus bens e família.

Qorpo Santo classificou "Duas páginas em branco" como apontamentos para uma comédia. No primeiro ato, Espertalínio leciona e namora a discípula Mancília. Depois de longo diálogo, ela se levanta e abraça o mestre, numa cena chocante para os pudibundos românticos:

“Mancília - (Abraçando o mestre.) Meu querido, meu amigo! eu sou tua, tu serás meu! Ainda tocaste-me e de tal modo, que de prazer quase mataste-me! Sim! Viveremos juntos para sempre!

Espertalínio - (Desprendendo-se de seus braços.) Sim, Mancília, eu te amo também; eu te adoro... eu te quero; eu te desejo e meu amor não é amores poéticos que aparecem hoje e apenas escritos sobre um quarto de papel desaparecem da imaginação e do coração daqueles que dizem consegui-los às suas amantes! É grande, é extenso, é forte e com sua densidade não há nuvem, não há céu que se compare por mais espesso que pareça!"

A avó se escandaliza com as carícias dos jovens e concorda com a união dos dois, porque eles se amam. Quando a avó se retira, entra uma menina que deseja saber o que os dois namora- 
dos faziam, pois quer apreender para ser sábia. Mancília manda a menina levar uma flor à avó e leva Espertalínio para o quarto.

O segundo ato é coerente com o anterior, mas inicia com duas mesas de bilhar na sala de visitas de Espertalínio, que, ao sair do quarto com a mulher, estranha as mesas e os dois jogadores; estes explicam que entraram porque a porta estava aberta. Espertalínio põe os dois a correr. O casal se assusta com os gritos de socorro, lá fora. Entram soldados da polícia que prendem Espertalínio pelo roubo de duas mesas de bilhar, apesar de seus protestos de inocência. Mancília, sozinha, fala de suas desgraças:

"Ai! que é isto, meu Deus! não bastavam os meus
sofrimentos morais (com a mão na testa) ainda es-
ta horrível dor de cabeça, que não sei como ainda
vivo; como falo; como penso; como discorro! ai!
(querendo caminhar, dando alguns passos) que so-
nho horrível é este mundo..."

Entre um tenente prepotente que se aboleta na casa, considerando-a como um hotel, apesar dos protestos de Mancília. Surge Espertalínio que desconfia da presença do militar impertinente, apesar de Mancília defender sua inocência. Depois que o tenente se retira, Espertalínio agarra a mulher pelos seios, levanta seus vestidos engomados, dizendo que está com fome e que quer comer. Ela responde:

"- Noivos não comem senão na cama (dando uns pulinhos); não bebem senão na cama. Portanto vamos para ela e lá o fartarei."

Esta comédia é a mais coerente de Qorpo Santo, explorando os mesmos temas de abuso da autoridade e de traição de mulher.

Na comédia "Dois irmãos", Qorpo Santo buscou colocar em cena os acontecimentos de sua vida, em forma de advertência para todos os que o desprezaram e o maltrataram. Em apenas um ato, com cinco quadros, que parecem desarticulados, mas estão ligados por pessoas que pertencem à mesma família e maltratam um personagem, o dramaturgo retoma a temática da injustiça, 
complementada com o arrependimento dos faltosos. O personagem, maltratado, injustiçado é chamado de Leva-Remos numa cena, em outra de Mateus e, na final, de Dr. Qorpo Santo.

O primeiro quadro apresenta personagens em diálogos exaltados e contraditórios, até que entra Frederico, filho do dono da casa. O rapaz, que tentou conversar com suas calças, casaco, colete e casaca, sem obter respostas, conta aos presentes que tem um amigo que alugou imóveis à Fazenda Nacional e não consegue receber os aluguéis, por causa de despachos e informações contraditórias em seu processo. Um procurador está utilizando os bens deste amigo, que é conhecido como doutor, filósofo, político, frade e botânico.

$\mathrm{Na}$ vida real, Qorpo Santo estava com seus bens interditados e queria continuar recebendo os aluguéis de suas propriedades. $\mathrm{O}$ quadro expressa suas dificuldades em assumir a realidade deste mundo.

No segundo quadro, Leva-Remos entra numa loja e o caixeiro dá-Ihe roupas para experimentar, que ora são grandes, ora são pequenas, provocando a fúria do comprador. $\mathrm{O}$ caixeiro quer Ihe dar as roupas, mas Leva-Remos murmura que amanhã irá cobrar e depois mandar o meirinho. Mesmo assim, veste as roupas. Por brincadeira, o caixeiro afirma que Leva-Remos quer roupa nova para beijar mulher nova. $O$ freguês tira a roupa e bate no caixeiro. O vendedor, ficando sozinho, arrepende-se de sua malvadeza, joga-se de joelho rezando, pois reconheceu em Leva-Remos (Qorpo Santo) o Homem-Deus. O patrão, vendo o empregado desmaiado, joga-o na rua. 0 mau caixeiro, por castigo, perdeu o emprego.

O terceiro quadro é uma brincadeira, possivelmente assistida por Qorpo Santo, ou protagonizada por ele num sarau. Um mágico, de nome Quadrado, quebra relógio, leque, manga de lampiao, mas não consegue fazer aparecer os objetos intactos. Um dos circunstantes apresenta para a platéia uma lição de moral:

"Circunstante - Aproveitamos a lição para não confiarmo-nos - de quem não conhecemos, nem cremos em impossíveis!" 
O quadro seguinte é uma parábola sobre as atribuições da mulher no lar, como reprodutora de filhos e do homem com sua missão de trabalhar.

Finalmente, no último quadro, o personagem Mateus solicita um cômodo ao chefe da casa, porque já está cansado dos vexames que passa nos hotéis por falta de dinheiro, pois seu procurador tudo the tirou. $\mathrm{O}$ dono da casa não lhe dá o quarto. Depois entra seu irmão que, ao saber do fato, torna-se aflito. Surge uma escrava oferecendo e franqueando a habitação de seu amo Mateus. O dono da casa desmaia de vergonha e seu irmão grita:

\section{“José - É possível que não haja nenhuma só pes- soa nesta casa que corra e vá chamar o doutor Qorpo Santo?"}

As comédias de Qorpo Santo foram marginalizadas em sua época, porque as duas correntes literárias, de então, o romantismo e o realismo, criaram a dramaturgia da verossimilhança, ou seja, a eficácia de uma ilusão da realidade. Os românticos, com suas histórias de príncipes e nobres, ciganos e camponeses, cegos e criados cômicos, procuraram explorar a expectativa em torno dos fatos que modificariam drasticamente a vida dos personagens: era a cigana que predizia a sorte da heroína, sempre uma pobre órfã que se tornaria rica; ou então o sinal na nuca ou a medalha que permitia descobrir o herdeiro de fabulosa fortuna. $O$ teatro realista, tentando transportar a vida para o palco, acabou descambando para o diálogo acadêmico, pedante, monótono e banal. Só as dramaturgias de Qorpo Santo e de Marins Pena escaparam destes lugares comuns, este pela leveza, aceleração de ritmo e criação de tipos populares, enquanto que aquele se caracteriza pela deformação do tempo e do espaço, através do encadeamento rítmico de auto-paródia, onde a própria ação não é explicada e nem solucionada.

Qorpo Santo criou uma atmosfera mágica que joga o leitor ou o espectador para a interioridade humana, denunciando as incoerências maldades e injustiças deste mundo real. A procura da justiça, os ressentimentos, a alienação social, ressoam, numa linguagem peculiar, dentro de discursos incoerentes, fora do plano cultural de sua época. 
Em seus bens de raiz, Qorpo Santo deixou uma casa em mau estado na vila de Triunfo, avaliada em cem mil réis, e o desejo testamentário de que seu corpo fosse embalsamado e levado para um mausoléu, para a referida vila. No túmulo haveria uma estátua com a inscrição sobre o peito:

"Quando o Direito não triunfa pela palavra, vence pela espada."

Façamos agora como no insólito teatro de Qorpo Santo: desce o pano bem devagar sobre este discurso, crônica, estudo ou comédia.

NOTA

* Professor do Departamento de História da PUCRS.

\section{BIBLIOGRAFIA}

AGUIAR, Flávio. Os homens precários. Porto Alegre, A Nação/SEC, 1975.

HESSEL, Lothar Francisco. O teatro no Brasil sob Dom Pedro II. Porto Alegre, URGS/IEL, 1979.

PORTO ALEGRE, Augusto. A fundação de Porto Alegre. Porto Alegre, Globo, 1909.

QORPO SANTO. Teatro completo - fixação do texto, estudo crítico e notas de Gui-

thermino César. Rio de Janeiro, Serviço Nacional de Teatro, 1980. 